\title{
A “DUEÑA” DE QUEVEDO Y VILLEGAS: ASPECTOS TRADUTÓRIOS AO PORTUGUÊS
}

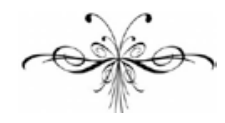

Andréa Cesco, BeAtrice TÁvora

Resumo: Este artigo apresenta e discute alguns aspectos das escolhas da tradutora Liliana Raquel Chwat referentes ao termo "dueña” e suas consequências para o leitor em língua portuguesa, na obra Sonhos do escritor barroco Francisco de Quevedo y Villegas (1580-1645), publicada pela editora Escala em 2005. Ela, que é considerada uma obra satírica, foi escrita no período compreendido entre os anos 1605 e 1622 e apresenta uma coleção de caricaturas sociais. A obra é fruto da genialidade de um mestre na utilização de figuras de linguagem, que utiliza palavras precisas a descrever cenas repletas de detalhes e capazes de transportar o leitor ao ambiente que retrata. A “dueña” aparece nestas cenas com características marcadamente culturais, cuja compreensão exige um conhecimento apurado de aspectos sócio-históricos envolvidos no texto de partida que se constituem desafios para o tradutor e que são aqui problematizados.

Palavras-chave: Sonhos. Dueña. Tradução. Quevedo y Villegas.

\begin{abstract}
Some aspects of the translation choices of the term "dueña” - including its consequences to Brazilian readers - made by Liliana Raquel Chwat in her translation into Portuguese of the satirical book Sueños $y$ Discursos, written in the $17^{\text {th }}$ century by Francisco de Quevedo y Villegas, compose the subject of this article. The translation was published by Escala in 2005. Quevedo y Villegas' satirical stories were written in the period between 1605 and 1622, and they showcase a collection of social caricatures. His work is the result of a master's genius in the use of figures of speech, as he employed precise words to describe scenes full of details that are able to transport the reader to the environment they portray. The term “dueña” appears in such scenes with markedly cultural characteristics whose understanding requires a thorough knowledge of sociohistorical aspects embedded in the source text, which in turn constitute challenges for the translator and are here critically discussed.
\end{abstract}

Keywords: Sueños y Discursos. Dueña. Translation. Quevedo y Villegas. 
$\mathrm{E}$ ste artigo busca problematizar as escolhas da tradutora Liliana Raquel Chwat para o termo dueña na obra Sonhos do escritor barroco Francisco de Quevedo y Villegas (1580-1645), publicada pela editora Escala em 2005, e discutir suas consequências para o leitor em língua portuguesa. Ela, que é considerada uma obra satírica, foi escrita no período compreendido entre os anos 1605 e 1622, e está constituída por cinco narrativas: "Sueño del Juicio”, “Alguacil endemoniado", "Infierno”, "El mundo por de dentro" e "El sueño de la Muerte”, que apresentam uma coleção de caricaturas sociais.

Quevedo teve uma produção literária intensa, abrangendo obras de caráter político-moral e satíricas que demonstram sua versatilidade ao expressar o mundo sob variados prismas, e que, ao mesmo tempo, são capazes de refletir traços de sua época. É considerado um homem típico do barroco, movimento artístico e literário próprio da cultura europeia pós-renascentista que, na visão de González (2010, p. 387), "preferirá o apelo à emoção, intensificando, para tanto, os recursos expressivos, no que se contrapõe à perspectiva crítica própria do Maneirismo”. Vizcaíno afirma que "o objetivo do barroco consiste [...] em estremecer, em violentar os sentimentos do homem e sacudi-los, ressaltando determinados retoques de efeito" (1985, p. 46).

A obra de Quevedo é fruto da genialidade de um mestre na utilização de figuras de linguagem. Ele utiliza palavras precisas que descrevem cenas repletas de detalhes capazes de transportar o leitor ao ambiente que retrata. Como afirma Vizcaíno (1985, p. 46), Quevedo domina a linguagem de tal forma que é capaz de superar os limites da expressão, com a pretensão de que, ao despedaçar sistematicamente ambientes e personagens, possa alcançar sempre um duplo efeito, de fundo e de forma.

Como ressalta Muller (1984, p. 241), Quevedo é capaz de reproduzir a realidade social através de seu equivalente verbal, imprimindo nos textos um realismo a toda escala sociolinguística de seu tempo, que engloba tanto o estilo elevado dos poetas e da literatura edificante quanto os jargões profissionais de juristas e médicos, gírias e ditos populares.

Dessa forma, o desafio do tradutor de Quevedo é trazer ao leitor em língua meta o efeito produzido por essa coleção de propriedades textuais, mantendo o que é dependente da forma, na tentativa de minimizar as inevitáveis tendências deformadoras apontadas por Berman (2007), cujo fim é a destruição da letra dos originais em benefício do sentido e da bela forma.

Assim, com a finalidade de verificar as escolhas tradutórias de Liliana Raquel Chwat para o termo dueña na obra Sonhos de Quevedo, apresentamos um trecho da narrativa “Sueño del Infierno" em que dueña aparece mais de uma vez. Nele, a voz satírica visita o inferno e descreve a situação de todos os personagens que ali estão, cujos vícios humanos encontram-se personificados e agrupados segundo um denominador comum. As citações abaixo apresentam grifos nossos para destacar as ocorrências do termo analisado.

Yo, que tenía gana de ver todo lo que hubiese, pareciendo que me había detenido mucho, me partí. Y a poco que anduve, topé una laguna muy grande como el mar, y más sucia, adonde era tanto el ruido, que se me desvanecía la cabeza. Pregunté lo que era aquello, y dijéronme que allí penaban las mujeres que en el mundo se volvieron en dueñas. Así supe cómo las dueñas de acá son ranas del infierno, que eternamente como ranas están hablando, sin ton y sin son, húmedas y en cieno, y son propiamente ranas infernales. Porque las dueñas ni son carne ni pescado, como ellas. Dióme grande risa el verlas convertidas en sabandijas tan 
pernabiertas y que no se comen sino de medio abajo, como la dueña, cuya cara siempre es trabajosa y arrugada. (QUEVEDO Y VILLEGAS, 1993, pp. 220221).

\title{
No texto traduzido de Chwat encontramos:
}

\begin{abstract}
Eu que tinha vontade de ver tudo, achando que já tivesse me detido muito, parti, e encontrei uma lagoa grande como o mar e mais suja, onde havia tanto barulho que me deixava zonzo. Perguntei o que era aquilo e me disseram que ali penavam as mulheres que se tornaram donas do mundo. Assim soube como as donas daqui são rãs do inferno, que eternamente como rãs estão falando sem tom nem som, úmidas e no lodo; são propriamente rãs infernais, porque não são carne nem peixe. Achei graça de vê-las transformadas em bichos de pernas abertas que só se comem da metade para baixo, como a dona cuja cara é sempre enrugada. (QUEVEDO Y VILLEGAS, 2005, p. 60).
\end{abstract}

De início, no contexto apresentado, pode parecer distante para o leitor brasileiro a escolha do conjunto "mulheres que se tornaram donas do mundo" porque o aspecto cultural que cerca o termo dueña é amplo e determinante. Em toda a tradução, o aspecto cultural deve ser observado, pois, como afirma Britto (2010), traduzir é um processo complexo de mediação cultural que deve considerar o grau de proximidade entre cultura-fonte e cultura-meta. Considerando-se então a diferença de culturas, podemos afirmar que o processo tradutório oscila no limite tênue entre o respeito ao original e a possibilidade de recriação, como explicita Antunes (1991), ao salientar que o original é sempre um ponto de partida que deve ser respeitado sem que isso signifique, porém, servilismo. A leitura mais profunda possível é que garantirá ao tradutor "a convicção necessária para criar numa língua, um texto que possa representar um original escrito numa outra” (ANTUNES, 1991, p. 8).

A busca de equivalências exige, dessa forma, um conhecimento apurado dos aspectos sócio-histórico-culturais envolvidos no texto de partida. Em relação ao trecho apontado, isso está expresso na necessidade de um exame mais aprofundado do termo dueña, que leve em conta sua evolução cultural na língua de partida.

Tomando então como ponto inicial o exame do léxico no idioma de partida, constatamos a existência dos vocábulos doña e dueña que designam mulheres com características distintas. Essa distinção pode não ser perceptível ao leitor brasileiro ante a ausência de diferenciação no idioma de chegada, que possui em seu léxico apenas o termo “dona”.

Com o intuito de esclarecer essa diferenciação, partimos do estudo da etimologia das palavras para distinguir doña e dueña, uma vez que, segundo o Diccionario de la Real Academia, ${ }^{1}$ o termo doña refere-se ao tratamento respeitoso que se aplica às mulheres e precede seu nome próprio e o termo dueña pode referir-se à mulher de propriedades, à beata que antigamente vivia em comunidade, à mulher viúva responsável pelo cuidado da criadagem que havia nas casas da nobreza e aristocracia, também à mulher casada, ou ainda à mulher que não era donzela. Ambas possuem sua origem no termo latino domina e em suas contrações domna e dona.

Francisco de Paula Mellado, na Enciclopedia Moderna, 15: Diccionario Universal de literatura, ciencias, artes, agricultura, industria y comercio (1852, pp. 103-107), apresenta a evolução do termo dueña e sua degradação ao longo do tempo. Afirma que na língua castelhana antiga o termo designava tanto a anciã viúva

${ }^{1}$ DRAE. Acesso em 26.04.2014. Disponível em http://www.rae.es/doña 
como a beata que vivia em comunidade, referindo-se, portanto, a mulheres dignas. Houve um período, segundo Mellado, em que se aplicou também às mulheres casadas cujos maridos tinham o privilégio de usar o pronome de tratamento Don, privilégio que ao longo do tempo passou a ser usado com demasiada liberdade, pois, já no século XIII consta em Las leyes de Partida (corpo normativo redigido no Reino de Castela durante o reinado de Alfonso X com o objetivo de conseguir uniformidade jurídica no Reino) que haviam se atrevido a isso muitos "oficiais mecânicos", e até mouros e judeus, razão pela qual deixou de ser usado pelos nobres nos séculos XIV, XV e XVI.

Essa degradação alcançou, consequentemente, o termo dueña que passou a designar título de servidão, endereçado à criadagem palaciana e comumente utilizado para nomear as mulheres que serviam, com toucas compridas, e para diferenciálas das donzelas. Esclarece ainda Mellado a existência de distintas classes de $d u$ eñas: as dueñas de honor, assim denominadas nos palácios as mulheres dignas que haviam enviuvado, e que as rainhas e princesas mantinham sempre perto de si; também nas casas honestas e com honra eram uma espécie de ama que servia para o decoro e guarda das donzelas; diferenciavam-se das dueñas de medias tocas em alusão às de classe inferior, diferenciadas pelo uso de toucas mais curtas, e que também eram conhecidas no palácio por dueñas de retrete.

A literatura, refletindo a realidade social, e ao longo do tempo, tomou o termo como base para a criação de inúmeros personagens. Conforme Gutiérrez (2003, p. 1), “este sentido objetivo, denotativo da palavra dueña, viu-se manipulado pejorativamente na literatura do século XVII ao ver sua figura construída no entremez e nas demais modalidades cômicas".

As viúvas de considerável idade, que eram obrigadas ao trabalho em razão das necessidades econômicas, passaram a exercer funções respeitáveis nas casas dos nobres ou junto à realeza, comandando a criadagem ou acompanhando suas senhoras. Outras, porém, dedicavam-se à prática de negócios pouco confiáveis, como a solução de seus problemas financeiros, dando origem à tradição folclórica da velha senhora em busca de um novo matrimônio, repleta de vícios de conduta, que utilizava artimanhas, mentiras e disfarces no intuito de alcançar seu objetivo: enriquecer. Como afirma Gutiérrez (2003, p. 2), “observa-se uma evolução nos motivos que a impulsionam a atuar - no entremezes renascentistas o erotismo, já nos barrocos a mulher é movida mais pelos valores materiais". 4

A figura da dueña, então, passa a constituir-se em um estereótipo feminino, abordada de diversas formas por numerosos escritores do período áureo, que constroem, inclusive, a pior imagem da velha senhora - perversa e manipuladora -, adicionando-lhe detalhes pitorescos ao longo do tempo e transformando-a em um tipo indispensável no romance e no teatro que vai até o século XVIII.

Esse estereótipo ganha contornos distintos na criação quevediana, pois, como afirma Ripoll (2005), são ressaltadas determinadas características grotescas e negativas através de metáforas que remetem aos mais diversos vícios humanos.

\footnotetext{
${ }^{2}$ Esse termo, "oficiais mecânicos”, se refere aos ferreiros, sapateiros e outras profissões executadas com as mãos.

3 “este sentido objetivo, denotativo de la palabra 'dueña' se vio manipulado peyorativamente en la literatura del siglo XVII al construirse su figura en entremeses y demás modalidades cómicas” (as traduções das citações, do espanhol para o português, são nossas).

4 “se observa una evolución en los móviles que la empujan a actuar - en los entremeses renacentistas el erotismo, mientras que en los barrocos la mujer se mueve más por valores materiales”.
} 
Existe um jogo permanente entre corrupção de costumes e transgressão moral capaz de criar adjetivos como: "alcoviteira de membros", "cozinheira de prazeres”, "facilitadora de pecados”, "proêmio de embustes”. Os tipos existentes na literatura satírica clássica são adaptados e ganham matizes.

Quevedo foi um dos escritores que mais denegriu a figura da dueña, e para isto ressaltou vários aspectos, tais como a idade avançada, a condição de viúva, de guardiã da honra das damas, de hipócrita, invejosa, cobiçosa, corruptora de costumes, organizadora de amores adúlteros, deixando evidente que por trás da aparência frágil da anciã carente escondia-se a mulher que concentrava uma série de vícios morais, refletindo na literatura hábitos de uma sociedade decadente, e cuja prática de encobrir e facilitar relações amorosas ilícitas, naquele período histórico, era considerado um ofício. O soneto intitulado "Epitafio de una dueña" espelha essa imagem:

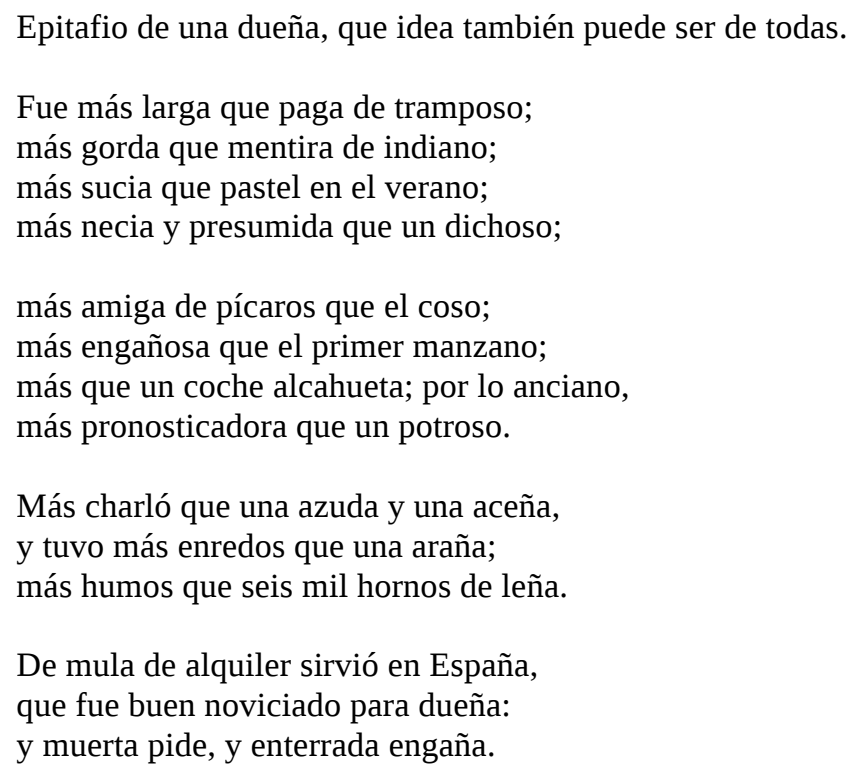

Segundo Cesco (2007), a dueña é uma personagem feminina de presença constante nas sátiras de Quevedo, e deriva provavelmente da figura popular da viúva alegre. Consistia em uma figura que habitava as casas dos nobres, andava sempre vestida de preto e usava uma touca branca, vestimenta que também passou a ser usada pelas monjas. Além de feias e impertinentes eram gulosas, fofoqueiras e subornáveis.

Muller, por seu turno, afirma no mesmo sentido que:

A dueña Quintañona, nome procedente de um romance que significa algo como “anciã centenária”, protesta de que abusem de seu nome para chamar com ele todas as dueñas, senhoras de companhia de casas nobres que encarnavam o falatório malicioso ${ }^{5}$ (1984, p. 241).

O próprio Quevedo em “Sueño de la Muerte” fornece algumas características desta personagem, comparando-a à inveja travestida em viúva, em jejum de todas as coisas, magra, com dentes amarelos e gastos que usava para morder o que

\footnotetext{
5 "La dueña Quintañona, nombre procedente de un romance que significa algo como "anciana centenaria”, protesta de que abusen de su nombre para llamar con él a todas las dueñas, señoras de compañía de casas nobles que encarnaban la murmuración maliciosa."
} 
havia de bom e de melhor. Ressalta-se aqui o duplo sentido do verbo morder que transcende sua significação literal para expressar o fato de que ela apreciava explorar os bens alheios e obter vantagens através de artimanhas.

A imagem de Quintañona, é transmitida minuciosamente, com um marco grotesco e cruel para descrever a figura literária da malvada velha decrépita que caminhava entre sepulturas carregando um cajado e usando toucas feitas de sua mortalha, além de um rosário de caveiras, semelhante a um espantalho, desprovida de dentes, com o rosto em forma de orelha, olhos encovados, testa enrugada, e nariz que, formando uma garra, conversava com o queixo.

No texto de Quevedo intitulado Discurso de todos los diablos, o Infierno enmendado, de 1627 (in RIPOLL, 2005), a figura da dueña também está presente, juntamente com a de um delator e a de um intrometido, formando um trio hábil a tumultuar ainda mais o inferno quevediano, lugar confuso e desordenado, onde não havia coisa com coisa, no qual todos se metiam nos castigos dos outros, e nem mesmo os demônios conseguiam controlar a situação.

Por todo o apresentado, verifica-se que o confronto entre duas culturas - a em língua espanhola do Séc. XVII e a em português do Brasil do Séc. XXI - fica claramente evidenciado e surge como um problema em termos tradutórios porque ao investigar as acepções da palavra "dona” em português vemos que elas em muito se distinguem das acepções históricas de “dueña” em espanhol.

Uma das primeiras referências encontradas para o termo "dona” em português é a que se encontra em Bluteau (1712, p. 287) para designar o título da mulher nobre ou mulher idosa que serve em uma casa, ou ainda para referir-se à avó na província de Entre Douro e Minho. Também, de acordo com Bluteau, o termo “dona de honor" era aplicado à mulher viúva que no palácio assistia a uma rainha ou a uma princesa, ou era o título dado às cônegas regrantes de Santo Agostinho, seja porque os cônegos da dita ordem se chamavam com o prenome Dom, seja porque as senhoras que professavam nela eram ilustres ou viúvas muito nobres, e no reino de Portugal eram chamadas “donas”, como em Castela o eram por dueña. Em Ferreira (1961, p. 425), encontramos "Senhora de alguma coisa; proprietária; título e tratamento honorífico que precede o nome próprio das senhoras: (Bras.) mulher; esposa”, e também em Magalhães (1960, p. 787), “o mesmo que senhora; é um apelativo respeitoso, que se antepõe ao nome próprio de uma senhora. Proprietária de alguma coisa; a que governa ou administra uma casa”. No dicionário eletrônico $\mathrm{Au}$ lete encontramos as referências à proprietária, mulher casada e como pronome de tratamento. ${ }^{6}$

Ainda que se considere a evolução da língua, como demonstrado pelos dicionários utilizados, que abrangem um largo período de tempo, em nenhum verbete existe a associação do termo “dona” ao uso pejorativo verificado em “dueña”. Na solução utilizada pela tradutora Liliana Raquel Chwat, o sentido da tradução de "y dijéronme que allí penaban las mujeres que en el mundo se volvieron en dueñas" assim expresso "e me disseram que ali penavam as mulheres que se tornaram donas do mundo" não encontra ressonância no texto fonte, e, ao contrário, desloca o leitor do significado original. Destarte, apresenta-se um personagem de maneira absolutamente fora de seu contexto histórico, tornando o trecho vazio diante da impossibilidade de associação entre a cena e o objeto da sátira. Portanto, existe no texto a alteração do sentido do termo, que no original remete à ideia da mulher fofoqueira e

\footnotetext{
${ }^{6}$ iDicionário Aulete. Lexicon Editora Digital. Acesso em 30.04.2012. Disponível em: http://aulete.uol.com.br/dona
} 
alcoviteira, que traduzida de outra forma aproximaria ao público receptor o verdadeiro sentido do original.

Também, em relação ao campo semântico, o conjunto original "mujeres que en el mundo se volvieron en dueñas", ao ser traduzido por "mulheres que se tornaram donas do mundo", no contexto em que se apresentam, distanciam-se do significado original. Pois o uso das preposições "do" e "no" pode alterar o valor semântico do texto. As frases "donas do mundo" e "donas no mundo”, por exemplo, transmitem sentidos diferentes, porque a primeira trata da posse de algo e a segunda dá caracterização de algo.

Vimos todo o exposto relacionado à evolução cultural do termo dueña, que remete à transformação da figura da mulher em um manancial de vícios e estereótipos de uma época, ou seja, sua transformação no mundo, que parte do ideal renascentista até chegar à degradação barroca; isso difere da mulher poderosa e proprietária de bens. Portanto, é a nós justo crer que a cena traçada por Quevedo contém essa mudança gradativa de valores que ocorreu no mundo, em que a caracterização de um grupo de mulheres transformou-se talvez como reação às condições que o próprio mundo lhes apresentava Além disso, a sátira de Quevedo gira em torno à corrupção dos valores, ou seja, os ideais de retidão e honestidade foram gradativamente se transformando no mundo em razão da degradação humana, dos defeitos de caráter e comportamento que são apresentados em toda a obra quevediana.

A tarefa do tradutor, que pretenda abarcar esse conteúdo satírico, reúne, portanto, uma complexidade de elementos que devem ser considerados para realizar a aproximação entre o conteúdo do texto fonte e o do texto meta, uma vez que não se refere apenas ao léxico, mas inclui uma escala de valores. Nesse sentido, em termos tradutórios, Fabri (apud Campos 1992, p. 32) diz que "não se traduz o que é linguagem num texto, mas o que é não-linguagem”, e aponta Bense que enfrentou o tema estabelecendo uma distinção entre "informação documentária”, “informação semântica” e "informação estética": documentária é aquela que reproduz algo observável; semântica a que acrescenta um elemento novo e não observável; e a informação estética está relacionada à surpresa, à improbabilidade da ordenação de signos e que não pode ser codificada, a não ser pela forma em que foi transmitida pelo artista. Assim, a posição de Campos aplica-se ao trecho que analisamos, que atrela a tradução de textos criativos à recriação, pois "numa tradução dessa natureza, não se traduz apenas o significado, traduz-se o próprio signo, ou seja, sua fisicalidade, sua materialidade mesma (propriedades sonoras, de imagética visual)” (1992, p. 35).

Autorizado então pela possiblidade de recriação, e considerando as possibilidades dentro do idioma de chegada, o conteúdo semântico do termo dueña, e de todos os valores que o cercam no trecho aqui analisado, talvez seja melhor expresso pelo uso da opção "alcoviteira", termo dicionarizado no português brasileiro para designar: "mulher que faz intrigas; mexeriqueira; mulher que serve de intermediária em relações amorosas"7 ou, ainda, através do termo "comadre" que designa a mulher bisbilhoteira e maledicente. ${ }^{8}$

\footnotetext{
${ }^{7}$ iDicionário Aulete. Lexicon Editora Digital, acesso em 26.04.2014, disponível em http://aulete.uol.com.br/alcoviteira

${ }^{8}$ iDicionário Aulete. Lexicon Editora Digital, acesso em 26.04.2014, disponível em http://aulete.uol.com.br/comadre
} 
Em qualquer tentativa de aproximação, o desafio do tradutor, que se configura no esforço pela expressão da não-linguagem, deve considerar também a afirmativa de Berman (1995, p. 02), para quem a essência do traduzir implica na destruição da letra, por um lado, e em sua manutenção, por outro, sendo necessário recorrer à análise de alguns fatores teoricamente denominados "tendências deformadoras" como forma de nos relacionarmos com a obra. Assim, no presente caso, operando-se a confrontação entre texto fonte e texto meta, entendemos tratar-se de uma “zona textual problemática”, ou seja,

aquela na qual aflora a imperfeição: de repente, o texto traduzido parece se enfraquecer, se contradizer, perder o ritmo [...] apresentar com brutalidade a palavra, [...] rebaixando a língua do original e testemunhando o fenômeno de contaminação linguística (1995, p. 2).

Assim, após uma breve discussão acerca do estilo do autor e dos recursos criativos utilizados, com elementos do contexto histórico que o cercava, na qual procuramos demonstrar a evolução e degradação do termo “dueña”, uma leitura crítica da tradução nos permitiu verificar que a solução trazida, embora tenha operado uma tentativa de aproximação dos termos em língua fonte e língua meta, não conseguiu expressar com precisão a força semântica e retórica do que se tem no texto fonte.

É fundamental também compreender que traduzir um texto como esse, do século XVII, envolve uma enorme empreitada, com muito estudo e sensibilidade por parte do tradutor, que precisa ser criativo, inovador, e ao mesmo tempo se preocupar em preservar com fidelidade elementos-chave do texto de partida.

Andréa Cesco

andrea.cesco@gmail.com

Universidade Federal de Santa Catarina

Beatrice Távora

tavorabeatrice@gmail.com

Universidade Federal de Santa Catarina 


\section{Referências bibliográficas}

ANTUNES, B. "Notas sobre a tradução literária". In Revista Alfa, v. 35, p.1-10, São Paulo, 1991. Acesso em 23.01.2013. Disponível em http://seer.fclar.unesp.br/alfa/article/view/3854

Bluteau, R. "Vocabulário Portuguez \& Latino: áulico, anatômico, architetonico...”, Coimbra: Collegio das Artes da Companhia de Jesu, 1712-1728, 8 v. Acesso em 03.06.2014. Disponível em www.brasiliana.usp.br/pt-br/dicionário/edição 1

BRITTO, P. H., “O tradutor como mediador cultural”. In Synergies Brésil, nº spécial 2, 2010, pp. 135-141. Acesso em 07.11.2013. Disponível em http://ressources-cla.univ-fcomte.fr/gerflint/Bresil_special2/britto.pdf

CAMPos, H. "Da tradução como criação e como crítica” In Metalinguagem e outras Metas. São Paulo: Perspectiva, 1992.

Cesco, Andréa. Sueños y discursos, de Quevedo: barroco, sátira e tradução. Florianópolis, SC, 2007. 207 f. Tese (Doutorado) - Universidade Federal de Santa Catarina, CCE. Programa de Pós-Graduação em Literatura.

Diccionario de la Real Academia Española. 22a edición. Acesso em 26.01.2013. Disponível em http://rae.es/

Ferreira, A.B. de H. Pequeno Dicionário da Língua Portuguesa. $10^{\mathrm{a}}$ ed. Rio de Janeiro: Codil, 1961.

GonzÁlez, M. M. Leituras de Literatura Espanhola: da Idade Média ao século XVII. São Paulo: Letraviva, Fapesp, 2010.

GutiéRreZ, E.B. "De Dueñas, Celestinas y Entremeses". Fundación Dialnet. Revista del CES Felipe II, $\mathrm{n}^{\circ}$ 0, 2003. Acesso em 17.01.2013. Disponível em http://dialnet.unirioja.es/servlet/articulo?codigo=3692542

Magalhães, A. Dicionário Enciclopédico Brasileiro. Vol. I. 7 ed. Porto Alegre: Editora Globo, 1960.

Mellado, F. P. Enciclopedia Moderna, 15: Diccionario universal de literatura, ciencias, artes, agricultura, industria y comercio. V. 15. Madrid: Establecimiento Tipográfico de Mellado, 1852.

Muller, F.W. “Alegoría y Realismo en Los 'Sueños' de Quevedo”. In Sobejano, G. (Org). Francisco de Quevedo. Madrid: Taurus Ediciones, 1984.

Quevedo y Villegas, Francisco de. Sueños y Discursos. Edición de James O. Crosby. Madrid: Clásicos Castalia, 1993.

. Os Sonhos. Trad. de Liliana Raquel Chwat. Grandes Obras do Pensamento Universal - 27. São Paulo: Escala, 2005.

Ripoll, M. M. El «Discurso de todos los diablos» de Quevedo. Estudio y edición. Madrid: Fundación Universitaria Española, 2005.

VizCAíno, J. A. Quevedo: Espejo Cóncavo del Imperio. Madrid: Silex, 1985. 